\title{
Modulation of rat hepatic CYP3A4 activity by Brassica oleracea, Hibiscus rosa sinensis, and Tradescantia zebrina
}

\author{
Chin Jin Han 1,*(D), Gabriel Akyirem Akowuah 2,*(D), Mohamed Saleem Abdul Shukkoor 2(D), \\ Anupam Biswas 1 (iD
}

1 Faculty of Medicine, Bioscience and Nursing, MAHSA University, Bandar Saujana Putra Campus, Jalan SP2, Bandar Saujana Putra, 42610 Jenjarom, Kuala Langat, Selangor, Malaysia

2 Faculty of Pharmaceutical Sciences, UCSI University, No. 1, Jalan Menara Gading, 56000, Cheras, Kuala Lumpur, Malaysia

* Correspondence: chinjinhan@mahsa.edu.my (C.J.H); agabriel@ucsiuniversity.edu.my (G.A.A);

Scopus Author ID 34167722100 (C.J.H.); 55887540600 (G.A.A.)

Received: 17.05.2020; Revised: 12.06.2020; Accepted: 14.06.2020; Published: 17.06.2020

\begin{abstract}
One of the major cytochrome P450s, CYP 3A4, is known to be involved in herb-drug and food-drug interactions. The objective of this study was to examine the in vitro effect of Brassica oleracea L. var. pekinensis (Chinese cabbage) juice, methanol extract of Hibiscus rosa sinensis (Hibiscus) yellow flower and Tradescantia zebrina pendula leaves, respectively on CYP 3A4 activity in rat liver microsomes. Differential centrifugation method was used to isolate microsomes from the rat livers. The concentration of formaldehyde released from $\mathrm{N}$-demethylation of aminopyrine in rat liver microsomes was determined. Based on the results obtained, B. oleracea juice at $100 \mathrm{ng} / \mathrm{mL}$ and 1000 $\mathrm{g} / \mathrm{mL}$ significantly reduced CYP3A4 activity when compared to the control group. On the other hand, methanol extract of Hibiscus yellow flower and T. zebrina leaves at 1, 10, 100, and $1000 \mathrm{ng} / \mathrm{mL}$ significantly increased the metabolism of aminopyrine by enhancing CYP3A4 activity when compared to the control group. Our findings suggested that Chinese cabbage juice, methanol extract of Hibiscus yellow flower, and T. zebrina leaves could have the potential to interact with the metabolism of aminopyrine in rat liver microsomes by modulating the hepatic CYP activity.
\end{abstract}

Keywords: Brassica oleracea; CYP3A4; Hibiscus rosa; Liver; Tradescantia zebrina.

(C) 2020 by the authors. This article is an open-access article distributed under the terms and conditions of the Creative Commons Attribution (CC BY) license (https://creativecommons.org/licenses/by/4.0/).

\section{Introduction}

The use of alternative medicines, such as herbal medicine, has been rapidly increasing worldwide [1]. Herbal medicine has received great attention in Asian due to its cost-effective, easily available, and generally safer compared to modern medicine. This has increased the chances of concurrent use of herbs and conventional drugs for treatment and to promote health. Therefore, possible herb-drug interactions could occur due to the concurrent use of herbal products and modern medication. Hibiscus rosa sinensis belongs to the Family of Malvaceae, and it is commonly known as hibiscus in many countries. It is an ornamental plant that is a native of China and distributed in Malaysia, India, Nepal, Bangladesh, Sri Lanka, and the Philippines. The fresh juice of the hibiscus flower is traditionally used to treat gonorrhea [2]. Hibiscus flower extract was reported to selectively induces apoptosis in breast cancer cells and positively interacts with common chemotherapeutics [3]. Flavonoids and anthocyanins are reported to be present in the yellow flowers of hibiscus. A clinical case has been reported on 
the possible interaction of hibiscus with chloroquine, a drug used in the treatment of malaria in a male subject.

Tradescantia zebrina pendula, (Family: Commelinaceae), previously known as Zebrina pendula Schnizl has an extended folk medicine use in the treatment of uterus ailments, hypertension, and tuberculosis [4]. T. zebrina leaves tea is commonly used to treat stomachache, body ache, and influenza in Mexico. Phytochemicals such as $\beta$-sitosterol, succinic acid, zebrinin, anthocyanin, flavonols, and apigenin have been identified in the leaves of T. zebrina [5]. Brassica oleracea L. var. pekinensis (Family: Brassicaceae) or generally known as Chinese cabbage, is eaten as a salad, cooked in a variety of dishes, or consumed as a juice. It is rich in flavonoids and anthocyanin. It has been proven by many scientific studies that antioxidants have a protective effect and healing properties on peptic ulcers [6].

Brassica oleracea, Hibiscus rosa sinensis, and Tradescantia zebrina are chosen for this study due to the presence of flavonoids and anthocyanin. Flavonoids are phytoconstituents known to affect the CYP3A4 enzyme levels in humans and laboratory animals. Therefore, we hypothesized that cabbage juice, hibiscus flower extract, and T. zebrina leaves extract could affect drug metabolism by modulating CYP3A4 enzyme activity in rat liver microsomes due to the presence of flavonoids. The main objective of this study was to investigate the in vitro effects of the Hibiscus yellow flower, T. zebrina leaves, and Chinese cabbage juice on the aminopyrine metabolism mediated by CYP3A4 in rat liver microsomes.

\section{Materials and Methods}

\subsection{Chemicals.}

Aminopyrine, barium hydroxide, phosphate buffer saline, ketoconazole, NADPH, magnesium chloride, zinc sulfate, ammonium acetate, acetone, and formaldehyde were purchased from a local supplier in Selangor, Malaysia. All chemicals used were at industrial graded.

\subsection{Preparation of Brassica oleracea Juice.}

Brassica oleracea or Chinese cabbage was obtained from a hypermarket located in Selangor, Malaysia. The fresh leaves of Chinese cabbage were used to prepare the juice by direct grinding without adding any solvent. The cabbage juice was freeze-dried and was stored in a refrigerator at $4^{\circ} \mathrm{C}$ until it was used for analysis.

\subsection{Preparation of Tradescantia zebrina Leaves extract.}

Fresh leaves of T. zebrina were obtained from Ipoh, Perak. The fresh leaves were manually separated from the stalks and air-dried in the lab for 7 days. The dried leaves were ground into dried powder $(16.7 \mathrm{~g})$ using a blender. Powdered dried leaves $(16.5 \mathrm{~g})$ were macerated with methanol $(500 \mathrm{~mL})$ in conical flasks for 3 days at room temperature $(25 \pm 2$ $\left.{ }^{\circ} \mathrm{C}\right)$. The solution was stirred using a magnetic stirrer. The conical flasks were covered with aluminum foil to reduce the possibility of photo-degradation of the constituents of the extracts. The extraction process was repeated until the process yield transparent filtrates. The mixture was filtered using filter paper (Double Rings, China) to remove insoluble materials and concentrated using a rotary evaporator (Büchi, Switzerland) at $40^{\circ} \mathrm{C}$. The concentrated crude extract was freeze-dried at $-50^{\circ} \mathrm{C}$ using a freeze dryer (Christ, Germany) for 24 hours. The 
freeze-dried extract ( $1.02 \mathrm{~g}$ ) was stored in the desiccator filled with silica desiccant to absorb remaining moisture until further usage.

\subsection{Preparation of Hibiscus yellow flower Extract.}

Fresh yellow color Hibiscus rosa sinensis flowers were collected from Kuala Lumpur, Malaysia. The flower petals were air-dried thoroughly under the shade and powdered and stored in an airtight container until subjected to solvent extraction. The grounded powder was extracted in a soxhlet apparatus using ethanol (1:10 ratio). The extract was filtered and concentrated in a rotatory evaporator at $30-40^{\circ} \mathrm{C}$ under reduced pressure.

\subsection{Determination of CYP $3 A 4$ activity.}

All the procedures for the present animal studies were performed in accordance with the ethical standards approved by the Institutional Animal Care and Use Committee, Faculty of Medicine, University of Malaya, Malaysia (Ethic No. 2016-170302/ANAT/R/WKH). Rat livers were obtained from 5 healthy male Sprague Dawley rats $(150 \pm 20 \mathrm{~g}$ body weight). Rat liver microsomes were prepared by differential centrifugation method [7]. The rat CYP3A4 activity was determined spectrophotometrically by measuring the formaldehyde released from $\mathrm{N}$-demethylation of its substrate aminopyrine [8-9]. Aminopyrine was used as a probe substrate in this study. The positive control group used for CYP3A4 assay was ketoconazole (5 mM). Incubation medium consisted of rat liver microsomes, aminopyrine (14 mM), NADPH (1 mM), phosphate buffer (0.1 M; pH 7.4), and Chinese cabbage juice, methanol extract of Hibiscus yellow flower and $T$. zebrina leaves at various concentrations (1-1000 ng/mL). The concentration of formaldehyde formed from CYP $3 \mathrm{~A} 4$ mediated $N$-demethylation of aminopyrine was calculated from the standard curve of formaldehyde plotted. The CYP 3A4 activity was expressed in nmol formaldehyde formed/minute/mg protein.

\subsection{Statistical Analysis.}

Data were presented as mean \pm standard deviation (S.D.). The data for the present study were analyzed by GraphPad Prism 5 using analysis of variance (ANOVA) following Dunnett's test to examine the significant differences of each treatment group and positive control group compared to the control group. With a confidence level of $99 \%(p<0.01)$, the difference would be considered as significant when the treatment group was compared to the control group.

\section{Results and Discussion}

Figure 1 showed the in vitro effect of Chinese cabbage juice on the CYP3A4 activity in rat liver microsomes. Chinese cabbage juices at $10 \mathrm{ng} / \mathrm{ml}(\mathrm{p}<0.01), 100 \mathrm{ng} / \mathrm{ml}(\mathrm{p}<0.01)$, and $1000 \mathrm{ng} / \mathrm{ml}(\mathrm{p}<0.01)$ showed a significant inhibitory effect on the CYP3A4 activity in rat liver microsomes compared with the control group. On the other hand, a significant increase in hepatic CYP3A4 activity was observed in the rat liver microsomes treated with methanol extract of Hibiscus yellow flower and T. zebrina leaves at a concentration of $1 \mathrm{ng} / \mathrm{ml}, 10 \mathrm{ng} / \mathrm{mL}$, $100 \mathrm{ng} / \mathrm{ml}$ and $1000 \mathrm{ng} / \mathrm{ml}(\mathrm{p}<0.01$ ) compared with the control group (Figures 2 and 3).

Aminopyrine $\left(\mathrm{C}_{13} \mathrm{H}_{17} \mathrm{~N}_{3} \mathrm{O}\right)$ is one of the commonly used probe substrates for the determination of CYP3A4 enzyme activity in experimental animals and humans. It was formerly used as an antipyretic and analgesic drug but was abandoned due to its side effects in humans after taking this drug. It is mainly metabolized via $\mathrm{N}$-demethylation to form 
monomethyl-4-antipyrine and formaldehyde, which can be measured by colorimetry Nash [8]. Aminopyrine $\mathrm{N}$-demethylase is equivalent to isoform CYP3A4 and closely related to the methylation reaction of drugs.

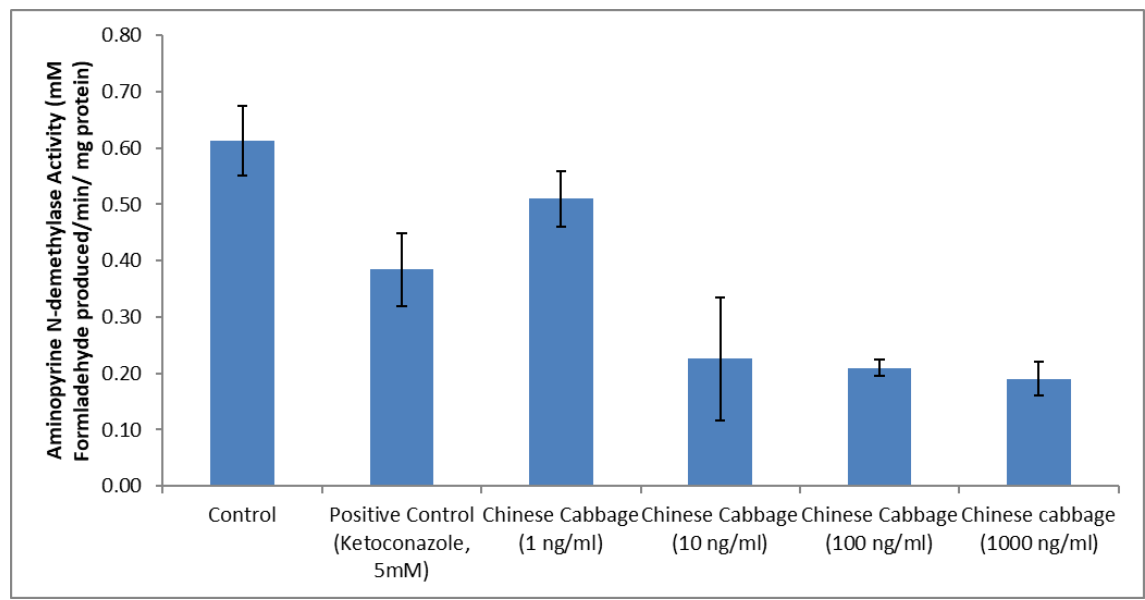

Figure 1. In vitro Inhibition of CYP3A4 Enzyme Activity by Brassica oleracea (Chinese cabbage) juice in Rat Liver Microsomes.

$\mathrm{n}=3$; Value $=$ mean \pm S.D; Analysed using post-hoc, Dunnett's Test

$* * p<0.01$ significant difference compared to the control group

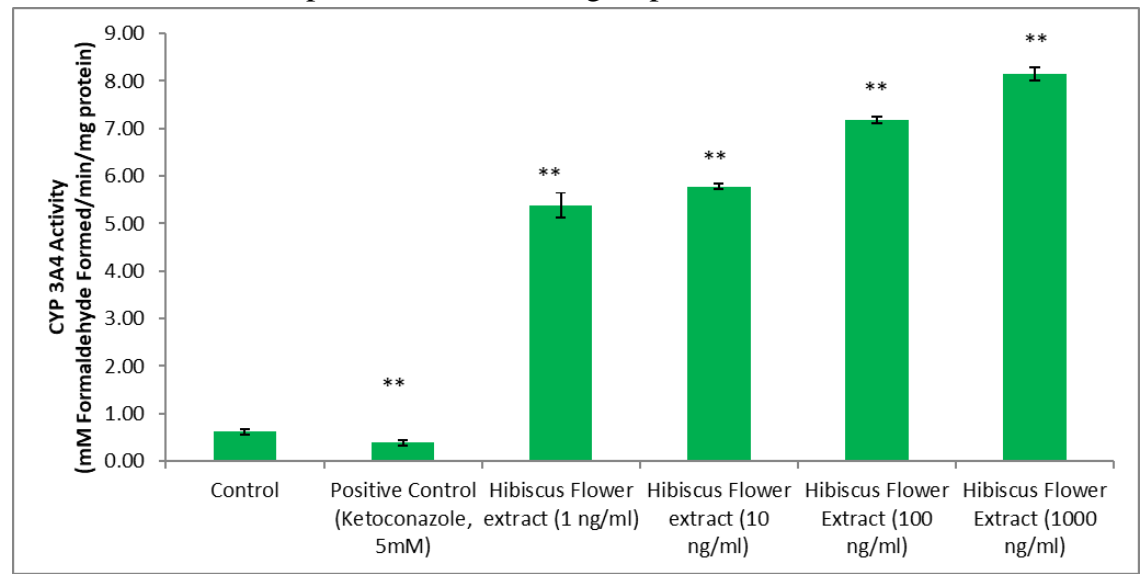

Figure 2. In vitro Induction of CYP 3A4 Enzyme Activity by Methanol Extract of Hibiscus Yellow Flower in Rat Liver Microsomes.

$\mathrm{n}=3$; Value $=$ mean \pm S.D; Analysed using post-hoc, Dunnett's Test

** $p<0.01$ significant difference compared to the control group

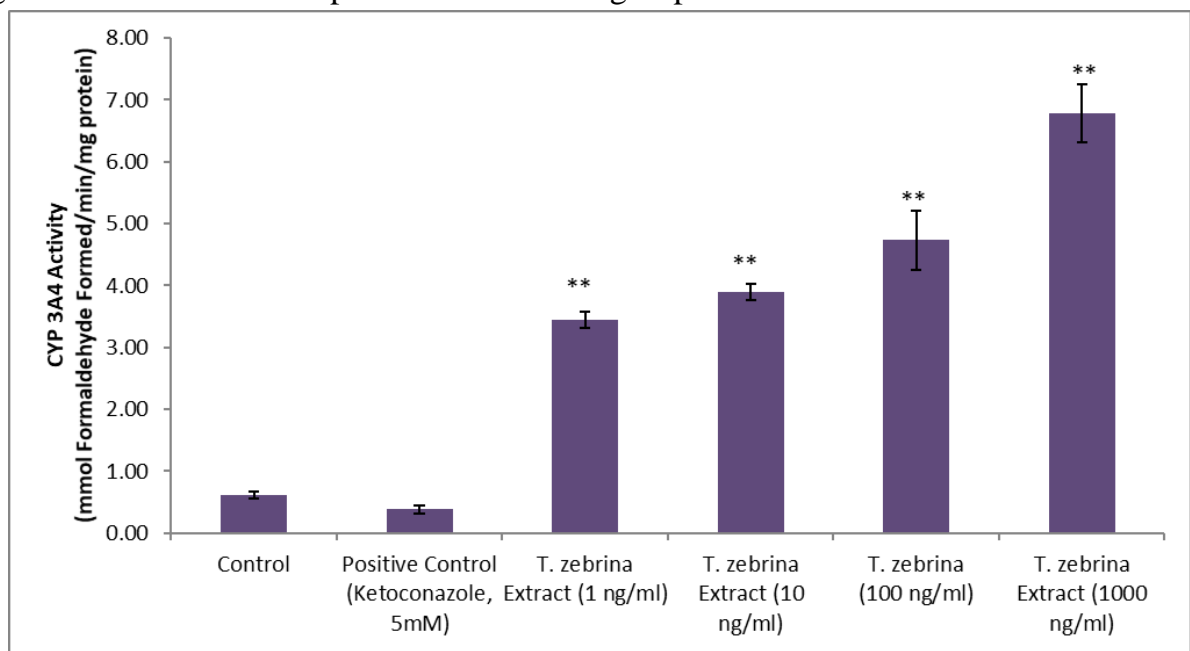

Figure. 3. In vitro Induction of CYP 3A4 Enzyme Activity by Methanol Extract of Tradescantia zebrina Leaves in Rat Liver Microsomes,

$\mathrm{n}=3 ;$ Value $=$ mean \pm S.D; Analysed using post-hoc, Dunnett's Test

** $p<0.01$ significant difference compared to the control group

https://biointerfaceresearch.com/ 
One of the important aspects of the discovery and development of drugs is to avoid drug interactions. However, herbal medicine is commonly assumed safe to be used as compared to conventional medicines. The changes in the CYP3A4 enzyme levels, which involve in the metabolism of many drugs are the most significant drug interaction that occurs with herbal products. CYP3A4 is the major metabolizing enzyme in the liver and intestine. Systems commonly used to assess drug metabolism include microsomes, recombinant enzymes, and hepatocytes. Microsomes, the subcellular fraction that is lacking cell membrane, provide ready access to the test compound to the targeted drug-metabolizing enzymes, such as CYP 3A4 in this study [9]. However, there are several biochemical mechanisms of pharmacokinetic and pharmacodynamics herb-drug interactions mediated by drug-metabolizing enzymes and transporters have been postulated. In addition to that, genetic polymorphisms have long been linked and are believed to be involved in pharmacokinetics and pharmacodynamics pathways that cause different drug responses [11]. Knowledge of mechanism underlying herb-drug interaction is essential to identify and prevent adverse interactions prospectively, as well as to modulate potentially beneficial interaction [12]. For example, combined therapy of garlic (250 $\mathrm{mg} / \mathrm{kg}$ ) with captopril demonstrated higher synergistic action with respect to fall in blood pressure and ACE inhibition [13]. Positive interaction between herbal medicinal products and a conventional drug, which showed a potential increase in drug efficacy and possible reduction of adverse effects had been reported [14].

Modulation of drug-metabolizing enzymes by plant extracts in the present study can reflect interactions with one or more herbal product constituents. The net effect can result from additive, synergistic or antagonistic interactions among multiple constituents. Our results indicated that Chinese cabbage juice at the concentration of $10 \mathrm{ng} / \mathrm{mL}$ and $100 \mathrm{ng} / \mathrm{mL}$ inhibited the activity of CYP3A4 in rat liver microsomes. Therefore, it has the potential to interact with the modern drugs that are metabolized by CYP3A4 enzyme. Drug-mediated inhibition of drug metabolizing enzymes is the most common and well-studied mechanism underlying pharmacokinetic drug interactions. It could be divided into reversible inhibition (competitive, non-competitive or uncompetitive) and irreversible inhibition. For example, the basis for grapefruit-drug interactions was irreversible inactivation (mechanism-based inhibition) of a crucial human drug-metabolizing enzyme, CYP3A4, particularly in the small intestines [15]. Inhibition of the CYP3A4 activity by Chinese cabbage juice can lead to an unwanted elevation of the in the blood levels of drugs administered concomitantly. This could delay the drug clearance from the liver and cause the accumulation of the drugs in the hepatic system, which eventually toxic to the liver. Drugs that are mainly metabolized by CYP3A4 include acetaminophen, diazepam, erythromycin, omeprazole, etc. However, the inhibitory effect on CYP3A4 in rat liver microsomes was not observed in the Chinese cabbage juice lesser than 10 $\mathrm{ng} / \mathrm{mL}$. On the other hand, T. zebrina leaves extract, and yellow hibiscus flower extract exhibited significant in vitro induction of CYP $3 \mathrm{~A} 4$ activities in rat liver microsomes. Common mechanisms of induction of drug-metabolizing enzymes include increased gene transcription or stabilization of mRNA or active protein.[16] As a result, T. zebrina leaves extract and yellow hibiscus flower extract could reduce the therapeutic outcomes of the drugs due to the shorter half-life in the circulation caused by the higher metabolism rate by hepatic enzymes. For example, St. John's wort has been reported to induce the higher metabolic activity of CYP3A4, leading to increased metabolites of omeprazole in a genotype-dependent manner [17]. Thus, there is a possibility that herb-drug interaction could occur with Chinese cabbage juice and Hibiscus yellow flower extract through their effect on CYP 3A4 enzyme in humans. 
Further research works are needed to isolate and identify the active ingredients responsible for the modulation effect on CYP3A4 activity in rat liver microsomes.

\section{Conclusions}

In conclusion, Chinese cabbage juice at $10 \mathrm{ng} / \mathrm{mL}, 100 \mathrm{ng} / \mathrm{ml}$, and $1000 \mathrm{ng} / \mathrm{mL}$ could be able to reduce aminopyrine metabolism by inhibiting the CYP3A4 activity. On the other hand, yellow hibiscus flower and T. zebrina leaves extracts induced the CYP3A4 activity in rat liver microsomes. In vivo study needs to be carried out further to confirm its effectiveness in the human body system.

\section{Funding}

This research was funded by MAHSA University, grant number RP84-11/15, and RP98-09/16.

\section{Acknowledgments}

The authors would like to thank the Faculty of Medicine, Bioscience and Nursing, MAHSA University, Bandar Saujana Putra, Selangor, Malaysia, for their support.

\section{Conflicts of Interest}

The authors declare no conflict of interest.

\section{References}

1. Khan, M.S.A.; Ahmad, I.; Chattopadhyay, D. New Look to Phytomedicine. 1st ed.; Academic Prese: London, United Kingdom, 2018; pp. 179-201.

2. Riaz, G.; Chopra, R. A review on phytochemistry and therapeutic uses of Hibiscus sabdariffa L. Biomed. Pharmacther. 2018, 102, 575-586, https://doi.org/10.1016/j.biopha.2018.03.023.

3. Nguyen, C.; Baskaran, K.; Pupulin, A.; Ruvinov, I.; Zaitoon, O.; Grewal, S.; Scaria, B.; Mehaidli, A.; Vegh, C.; Pandey, S. Hibiscus flower extract selectively induces apoptosis in breast cancer cells and positively interacts with common chemotherapeutics. BMC Complement. Altern. Med. 2019, 19, https://doi.org/10.1186/s12906-019-2505-9.

4. Ribeiro, D.B.; Fabricante, J.R.; Albuquerque, M.B. Bioinvasion of Tradescantia zebrina Heynh. (Commelinaceae) in uplands, State of Paraíba. Brazil J Biol Sci. 2014, 1, 1-10, https://doi.org/10.21472/bjbs.010101.

5. Idaka, E.; Ohashi, Y.; Ogawa, T.; Kondo, T.; Goto, O. Structure of zebrinin, a novel acylated anthocyanin isolated from Zebrina pendula. Tetrahedron Lett. 1987, 28, 1901-4, https://doi.org/10.1016/S00404039(00)96005-2.

6. Elsaed. W.M.; Alahmadi, A.M.; Al-Ahmadi, B.T,C.; Jumana A. Taha, J.A.; Tarabishi, R.M. Gastroprotective and antioxidant effects of fluvoxamine on stress-induced peptic ulcer in rats. J. Taibah. Univ. Med. Sci. 2018, 13, 422-431, https://doi.org/10.1016/j.jtumed.2018.04.010.

7. Whalley, P.M.; Karin M.B.; Bentley, S.; Corvaro, M; Funk, D.; W.Himmelstein, M.W.; fBirgitNeumann, B.; Strupp, C.; Zhang, F.; Mehta, J. An in vitro approach for comparative interspecies metabolism of agrochemicals. Regul Toxicol Pharmacol. 2017, 88, 322-327, https://doi.org/10.1016/j.yrtph.2017.03.020.

8. Nash, T. The colorimetric estimation of formation of formaldehyde means of Hantzsch reactions. J Biol Chem. 1953, 55, 416-422, https://dx.doi.org/10.1042\%2Fbj0550416.

9. Akowuah, G.A.; Chin J.H.; Yeong S.W.; Quah, S.Y.; Ahmad, M. In-Vitro CYP3A4, CYP2E1 and UGT activity in human liver microsomes by Strobilanthes crispus leaf extracts. The Nat. Prod. J. 2020, 10, 104112, https://doi.org/10.2174/2210315509666190304124328.

10. Tsaioun, K.; Kates, S.A. ADMET for Medicinal Chemists A Practical Guide. John Wiley \& Son, Inc.: New Jersey, USA, 2011; pp. 17-20, https://doi.org/10.1002/9780470915110.

11. Campion, D.P.; Dowell, F.J. Translating Pharmacogenetics and Pharmacogenomics to the Clinic: Progress in Human and Veterinary Medicine. Front. Vet. Sci. 2019, 6, 1-11, https://doi.org/10.3389/fvets.2019.00022.

12. Hogle, B.C.; Xiudong Guan, X.; Maggie Folan, M.M.; Wen X. PXR as a mediator of herb-drug interaction. J Food Drug Anal. 2018, 26, S26-S31, https://doi.org/10.1016/j.jfda.2017.11.007. 
13. Asdaq, S.M.; Inamdar, M.N. Potential of garlic and its active constituents, S-allyl cysteine, as antihypertensive and cardioprotective in presence of captopril. Phytomed. 2010, 17, 1016-1026, https://doi.org/10.1016/j.phymed.2010.07.012.

14. Pezzani, R.; Salehi, B.; Vitalini, S.; Iriti, M.; Zuñiga, F.A.; Sharifi-Rad, J.; Martorell, M.; Martins, N. Synergistic Effects of Plant Derivatives and Conventional Chemotherapeutic Agents: An Update on the Cancer Perspective. Medicina 2019, 55, https://doi.org/10.3390/medicina55040110.

15. Lown, K.S; Bailey, D.G.; Fontana, R.J.; Janardan, S.K.; Adair, C.H.; Fortlage, L.A. Grapefruit juice increases felodipine oral availability in humans by decreasing intestinal CYP3A protein expression. J. Clin Invest. 1997, 99, 2545-2553, https://doi.org/10.1172/JCI119439.

16. Schneider, E.K. Cytochrome P450 3A4 Induction: Lumacaftor versus Ivacaftor Potentially Resulting in Significantly Reduced Plasma Concentration of Ivacaftor. Drug Metab. Lett. 2018, 12, 71-74, https://doi.org/10.2174/1872312812666180328105259.

17. Wang, L.S.; Zhou, G.; Zhu, B. St John's wort induces both cytochrome P450 3A4-catalysed sulfoxidation and 2C19-dependent hydroxylation of omeprazole. Clin Pharmacol Ther. 2004, 75, 191-197, https://doi.org/10.1016/j.clpt.2003.09.014. 